\title{
Experimental Study on Uniaxial Compression of Bamboo Nodes Using 3D Scanning Technique
}

\author{
Xinmiao Meng ${ }^{1, *}$, Han Sun $^{1}$, Yuyang Cao ${ }^{1}$ and Peng Feng ${ }^{2}$ \\ ${ }^{1}$ Department of Civil Engineering, Beijing Forestry University, Beijing, China. \\ 2 Department of Civil Engineering, Tsinghua University, Beijing, China.
}

\begin{abstract}
Bamboo is a kind of ecological building material for its physical and mechanical characteristics, such as fast growth, high yield, high strength, high toughness and good environmental performance. However, there are few studies on the influence of bamboo node structure about the mechanical properties of bamboo, and it is difficult to accurately determine the cross-section area of the bamboo node. In this paper, the three-dimensional scanner was combined with the reverse modeling technology to accurately obtain the cross-sectional area of the bamboo node. The bamboo node was subjected to axial compression test. Based on the experimental results, it was confirmed that the compressive strength of the bamboo node increased from the bottom to the top. The experimental results also showed that the difference in the degree of cracks has an effect on the bamboo break mode. Bamboo nodes with severe cracks and uneven distribution on the surface had the largest degree of expansion at the original deep cracks or the original surface through cracks. Bamboo nodes with slight cracks and even distribution or without cracks on the surface were uniformly expanding at the lower part when they were broken.
\end{abstract}

\section{Introduction}

The natural bamboo pole is a lightweight functional gradient material [1-4] with a hollow cylindrical shape, which is rich in yield [5], fast in growth, cheap and economical, and environmentally friendly [6]. It is an ecological building material that needs to be developed and utilized [7, 8]. Therefore, the study of bamboo is of great significance.

The overall structure of bamboo is a hollow structure with a decreasing cross-sectional area from the bottom. A bamboo node appears every few centimeters to several tens of centimeters. The partition and the inner wall of the bamboo form a monolithic structure that is closely interdigitated in the longitudinal and vertical directions. This is essential for the stiffness and stability of slender bamboo [9]. However, the influence of bamboo nodes on the mechanical properties of bamboo is rarely studied in the current literature, and no unified conclusion has been drawn. Zenita et al. [10] has shown that the compressive strength of the bamboo node increases with its height position in the bamboo; Gusti et al. [11] has shown that the compressive strength of the bamboo nodes and the internodes from the bottom to the top is almost similar. Shao et al. $[9,12]$ has shown that bamboo nodes have no reduced effect on the compressive strength of bamboo, but there are different degrees of enhancement. The above researches respectively used the raw bamboo specimen and the bamboo specimen which removes the bamboo-green and bamboo-yellow as the research object. However, they did not propose scientific and accurate measurement methods for the cross-sectional area of the bamboo nodes, which is relatively rough.

Therefore this paper will use 3D scanning technique [13-14] to obtain the three-dimensional model of the bamboo node, which can accurately obtain the crosssectional area of the bamboo node. Through the axial compression test of the bamboo nodes, the influence of the position of the bamboo node in the bamboo on the axial compressive strength of the bamboo nodes will be analysed and the differences of failure modes influenced by different crack conditions will be summarized.

\section{Experimental Program}

\subsection{Specimens}

The bamboo was from Xianning, Hubei Province. The bamboo was about 15 meters in length. The moisture content of the bamboo pole is about 15\%. 18 bamboo nodes were cut from three natural bamboos. The specimen was named as $x-y-z-o$, where $x, y, z$, and $o$ represented the group of the bamboo, the position of the bamboo node, the segmentation shape of the bamboo, and the degree of cracking. The group of bamboo was called A, B, C. The selected bamboo nodes were numbered from the top to the bottom from the number 1 . The segmentation pattern in the bamboo was divided into upper convex (uc), lower convex (lc) and wave (w). The degree of crack was divided into three categories: no crack $(\mathrm{N})$, slight crack (L), and severe crack (S).

\footnotetext{
* Corresponding author: mengxinmiao@bjfu.edu.cn
} 
Table 1. The details of specimens

\begin{tabular}{|c|c|c|c|}
\hline Specimens & $\begin{array}{c}\text { Area } \\
\mathbf{( m m}^{\mathbf{2}} \mathbf{(}\end{array}$ & $\begin{array}{c}\text { Height } \\
\mathbf{( m m )}\end{array}$ & Cracks \\
\hline A-1-uc-L & 978.6 & 81.6 & Slight \\
\hline A-2-b-L & 1037.3 & 74.0 & Slight \\
\hline A-3-uc-L & 1087.0 & 89.4 & Slight \\
\hline A-4-b-N & 1182.6 & 81.0 & None \\
\hline A-5-b-L & 1281.4 & 96.8 & Slight \\
\hline A-6-b-L & 1304.9 & 116.6 & Slight \\
\hline A-7-b-N & 1370.9 & 97.5 & None \\
\hline A-8-w-N & 1766.1 & 92.0 & None \\
\hline B-1-uc-S & 1258.6 & 78.6 & Severe \\
\hline B-2-b-S & 1352.7 & 95.5 & Severe \\
\hline B-3-b-S & 1428.1 & 103.0 & Severe \\
\hline B-4-b-S & 1611.7 & 99.0 & Severe \\
\hline B-5-b-S & 1759.0 & 94.5 & Severe \\
\hline C-1-uc-S & 1022.2 & 67.8 & Severe \\
\hline C-2-uc-S & 1084.2 & 73.4 & Severe \\
\hline C-3-uc-S & 1214.5 & 86.6 & Severe \\
\hline C-4-w-S & 1271.5 & 94.5 & Severe \\
\hline C-5-uc-S & 1477.4 & 125.5 & Severe \\
\hline
\end{tabular}

\subsection{Experimental setup and instrumentations}

FreeScanTMX3 laser 3D scanner was used to obtain point cloud data. It could obtain the parameters such as the loaded area, height and wall thickness of the bamboo nodes compression test more accurately. It was also effective to compare the bamboo nodes after the test, analyze the bamboo cracks, the presence or absence of the groin and other factors of the bamboo nodes.

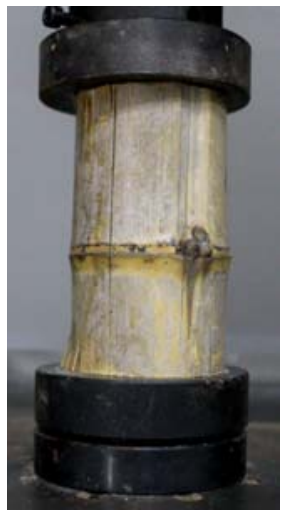

(a) Experimental setup

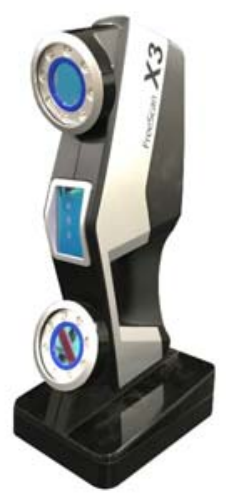

(b) 3D scanner
Fig. 1. Experimental setup and instrumentations

\section{Experimental Program}

\subsection{General observation}

At the beginning of the loading, the bamboo nodes were slowly compressed, and a slight sound might occur. At the same time, the curve rose linearly. Then the curve began to soften slowly. When the load increased to the peak load, the cracks developed rapidly, the lower part of the bamboo node gradually expanded, and the bearing capacity decreased rapidly, accompanied by a relatively loud sound. Then the crack developed and the bearing capacity of the bamboo nodes continued to weaken.

The load-displacement curve is shown in Figure 2. It can be seen that the axial compression of the bamboo node can be divided into three stages: (I) Linear growth stage, where the load and deformation were basically linear; (II) The unstable development stage of the crack. The bamboo node was continuously compacted, and micro cracks first appeared in some weak parts. The redistribution of stress at cracks causes the damage of the weak part, but the carrying capacity was still increasing until the peak load was reached. (III) failure stage. When the peak strength was reached, the micro cracks rapidly developed longitudinally through the bamboo node, and the damage surface increased. The bamboo seriously damaged and the carrying capacity continuously weakened.

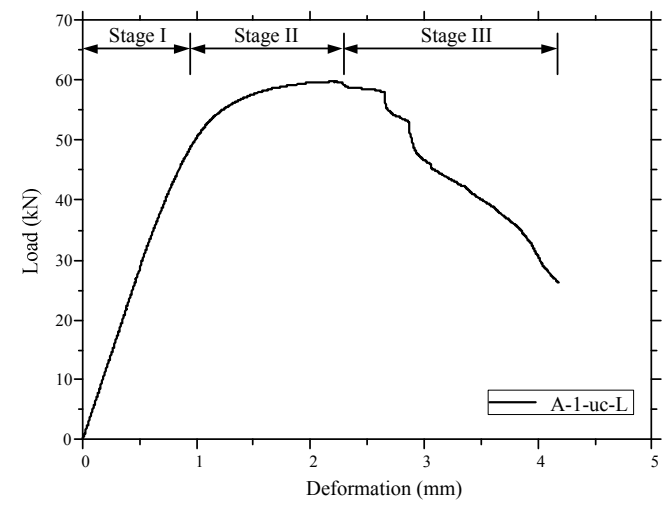

Fig. 2. Typical axial load-displacement curves

\subsection{Crack developments}

For the bamboo nodes with severe cracks and uneven distribution on the surface, after the peak load, the original cracks continued to expand and rapidly penetrated the surface longitudinally. The damaged positions increased, and the lower part of the bamboo node expanded unevenly. The general trend is that the original deep cracks or the original surface through cracks had the largest degree of expansion.

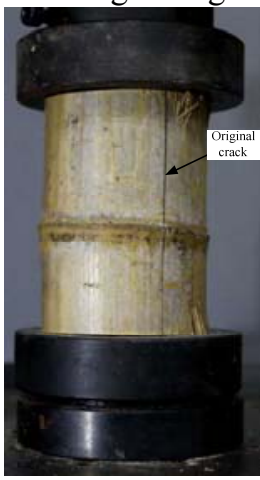

(a) Before test

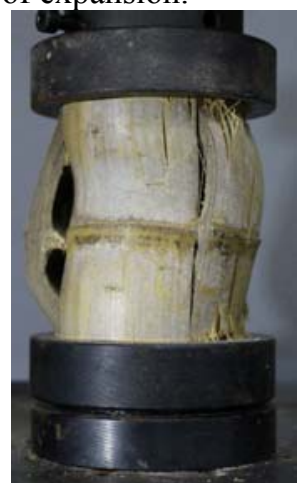

(b) Failure modes
Fig.3. Uneven-crack failure modes 
As for the bamboo nodes with slight cracks, no cracks or even cracks distributed on the surface, after reaching the peak load, the vertical cracks appeared evenly on the surface, and then the cracks ran through the bamboo nodes and the lower part of the bamboo nodes were uniformly expanded.

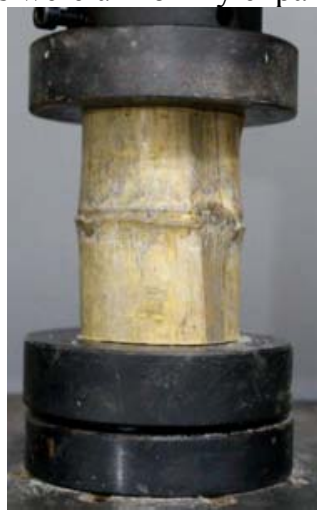

(a) Before test

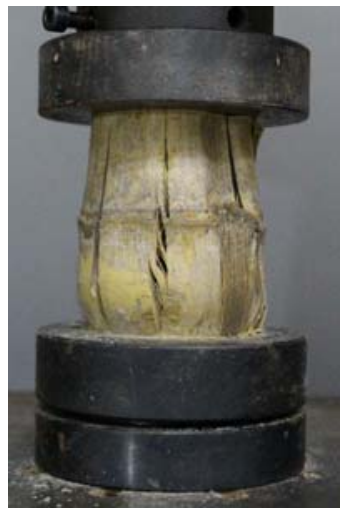

(b) Failure modes
Fig.4. Even-crack failure modes

\section{Results and discussion}

\subsection{Capacity and deformation}

The results of the axial compressive strength of the bamboo nodes located in different positions of bamboo are shown in the Table 2 below.

Table 2. The experimental results of specimens

\begin{tabular}{|c|c|c|c|}
\hline Specimens & $\begin{array}{c}\text { Area } \\
\left(\mathbf{m m}^{2}\right)\end{array}$ & $\begin{array}{c}\text { Peak load } \\
\mathbf{( k N )}\end{array}$ & $\begin{array}{c}\text { Maximum } \\
\text { stress (MPa) }\end{array}$ \\
\hline A-1-uc-L & 978.6 & 59.8 & 61.1 \\
\hline A-2-b-L & 1037.3 & 63.6 & 61.3 \\
\hline A-3-uc-L & 1087.0 & 65.0 & 59.8 \\
\hline A-4-b-N & 1182.6 & 70.9 & 59.9 \\
\hline A-5-b-L & 1281.4 & 74.5 & 58.1 \\
\hline A-6-b-L & 1304.9 & 76.5 & 58.6 \\
\hline A-7-b-N & 1370.9 & 76.5 & 55.8 \\
\hline A-8-w-N & 1766.1 & 95.6 & 54.1 \\
\hline B-1-uc-S & 1258.6 & 67.4 & 53.5 \\
\hline B-2-b-S & 1352.7 & 75.4 & 55.7 \\
\hline B-3-b-S & 1428.1 & 78.6 & 55.0 \\
\hline B-4-b-S & 1611.7 & 87.6 & 54.3 \\
\hline B-5-b-S & 1759.0 & 95.1 & 54.1 \\
\hline C-1-uc-S & 1022.2 & 60.1 & 58.8 \\
\hline C-2-uc-S & 1084.2 & 68.7 & 63.4 \\
\hline C-3-uc-S & 1214.5 & 81.4 & 67.0 \\
\hline C-4-w-S & 1271.5 & 84.5 & 66.4 \\
\hline C-5-uc-S & 1477.4 & 93.0 & 63.0 \\
\hline
\end{tabular}

In the group $\mathrm{A}$, the specimens with the same segmentation shape (lc) and similar crack conditions, the axial compressive capacity was consistent with the rule of increasing from the bottom of the bamboo to the top. The compressive capacity of the specimens A-1-uc-L and A-3-uc-L were lower than those of the specimens A1-lc-L and A-4-lc-N, respectively. Moreover, the specimens A-1-t-L and A-3-t-L still conformed to the law that the compressive capacity of the bamboo node increased from the bottom of bamboo to the top (Fig. 5).

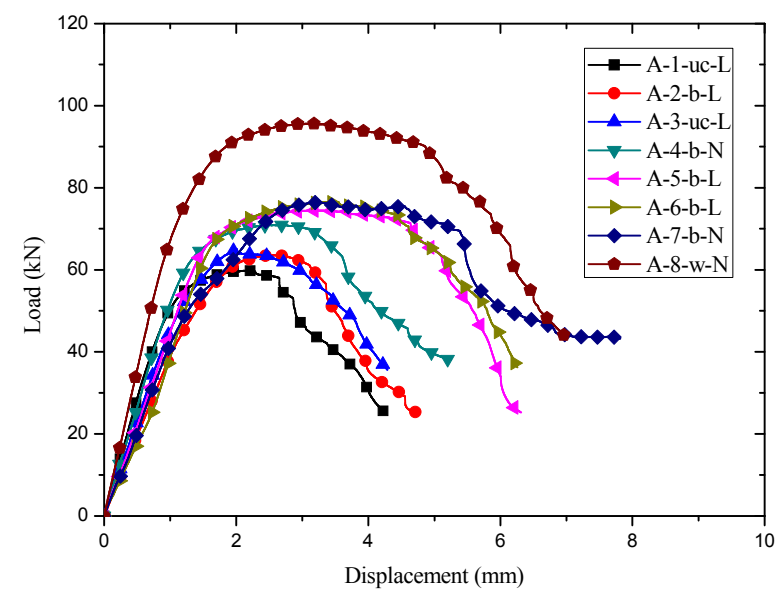

Fig.5. Load-displacement curves of Group A

In the group $\mathrm{B}$, the specimens with the same segmentation shape (lc) and similar cracks had a compressive capacity consistent with the law of increasing from the bottom to the top of the bamboo. The compressive capacity of B-1-uc-S is lower than that of B-2-lc-S (Fig. 6).

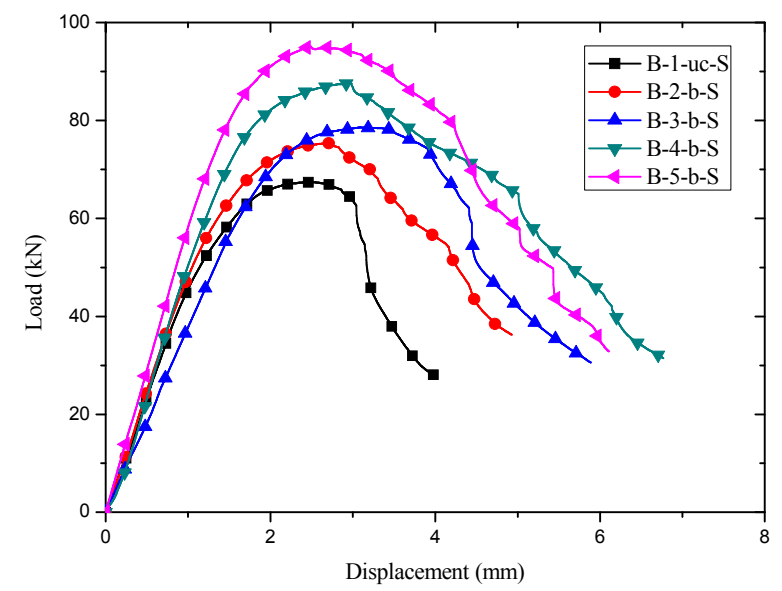

Fig.6. Load-displacement curves of Group B

In the Group $\mathrm{C}$, the compressive capacity of the specimens $\mathrm{C}-5$ to $\mathrm{C}-3$ was consistent with the law of increasing from the bottom of the bamboo to the top (Fig.7). The specimens C-1-uc-S and C-2-uc-S had deep cracks, which had a great influence on the compressive strength of the bamboo nodes, so the compressive capacities were reduced to some extent. Although the C1-uc-S had only one deep crack, during the test, the bamboo node showed uneven expansion on the side of the deep crack. After the bearing capacity reached the peak value, the force-deformation curve did not undergo the softening stage and decreased rapidly. The three deep cracks of the specimen C-2-uc-S were evenly distributed. During the test, the bamboo nodes showed uniform 
expansion, and the bearing capacity reached the peak load and then experienced the softening stage. Therefore, the compressive strength of C-1-uc-S was less than that of the C-2-uc-S.

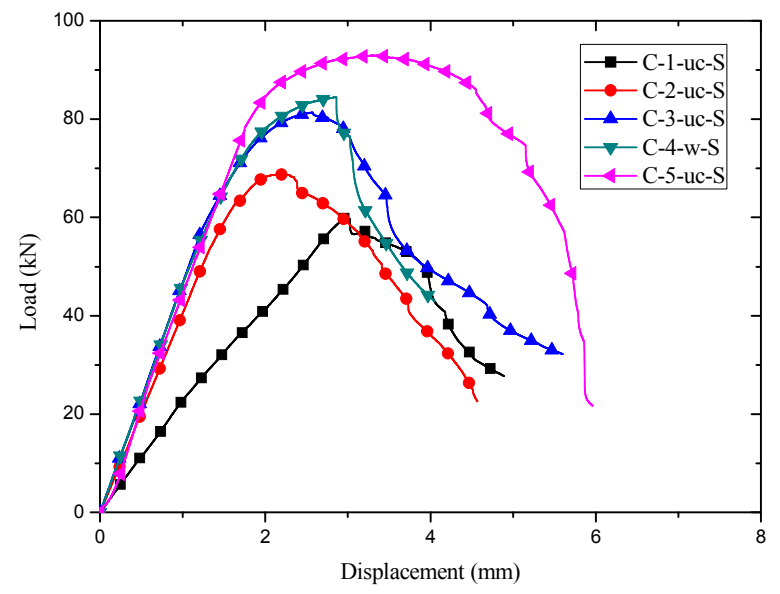

Fig.7. Load-displacement curves of Group C

This indicates that the axial compressive capacity of the bamboo nodes with the same shape and similar crack conditions is consistent with the rule of increasing from the bottom to the top of the bamboo. At the same time, the segmentation shape has an effect on the axial compressive capacity of the bamboo node. The test results show that the upper convex section will reduce the axial compressive capacity of the bamboo node to a certain extent, and the degree of weakening is not large. The test results also show that the degree of cracks in the nodes and the shape of the cracks have an effect on the compressive capacity of the bamboo nodes.

\subsection{Application of the 3D scanning technique}

In this experiment, the point cloud data was obtained using the three-dimensional scanner. The collection method is non-contact measurement, which can quickly scan the entire bamboo node specimen with large measurement area and high detail resolution [13]. The obtained point cloud data was imported into the Geomagic Studio software to perform point cloud data rendering to increase the stereoscopic realism and facilitate subsequent operations [14]. The data processing process is a key link in the reverse modeling technology. There are many noise points when scanning the bamboo nodes. The noise points have a bad influence on the subsequent modeling of the bamboo nodes. Therefore, it is necessary to process the noise points and the isolated points in the point cloud data, in addition, need to fill the missing point cloud data.

The processed point cloud data of the bamboo node sample was packaged to obtain a three-dimensional model of the bamboo node. The Figure 8 is a threedimensional perspective and cross-section views of the bamboo node specimen.

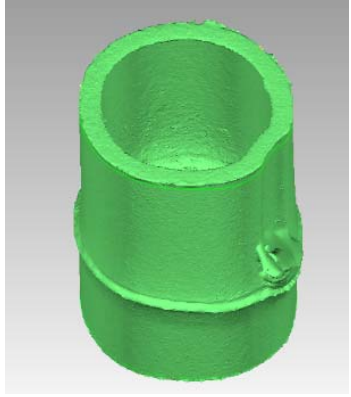

(a) perspective view

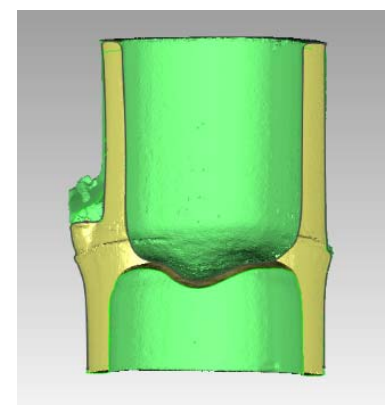

(b) cross-sectional view
Fig.8. 3D scanning views

\section{Conclusion}

In this paper, the uniaxial compression tests of the bamboo nodes were conducted. The influence of the height position of bamboo nodes in the bamboo against the compressive capacity was analysed and verified, and the failure modes of different crack degrees were summarized. Additionally, the three-dimensional scanner was used with the reverse modeling technology.

(1) The axial compression test results of the bamboo nodes showed that in the same bamboo, the axial compressive strength of the bamboo nodes basically conformed to the law of increasing from the bottom to the top.

(2) Bamboo nodes with severe cracks and uneven distribution on the surface had the largest degree of expansion at the original deep cracks or the original surface through cracks. Bamboo nodes with slight cracks and even distribution or without cracks on the surface were uniformly expanded at the lower part when they were broken.

(3) The method of using the 3D scanner combined with the reverse modeling technique to obtain the threedimensional model of the bamboo node, the internal morphological features and the geometric parameters such as the height and the cross-sectional area has a certain reference for the future research on bamboo.

\section{Acknowledgments}

The authors acknowledge funding supported by the Fundamental Research Funds for the Central Universities of China (No. BLX201706), and supported by Major Science and Technology Program for Water Pollution Control and Treatment (No.2017ZX07102001), and supported by the National Natural Science Foundation of China (No. 51278276 and No. 51522807).

\section{References}

[1] Tan T, Rahbar N, Allameh S M, et al. Mechanical properties of functionally graded hierarchical bamboo structures. Acta Biomaterialia, 2011, 7(10): 3796-3803.

[2] Amada S, Ichikawa Y, Munekata T, et al. Fiber texture and mechanical graded structure of bamboo. Composites Part B: Engineering, 1997, 28(1-2): 13-20. 
[3] Nogata F, Takahashi H. Intelligent functionally graded material: bamboo. Composites Engineering, 1995, 5(7): 743-751.

[4] Habibi M K, Samaei A T, Gheshlaghi B, et al. Asymmetric flexural behavior from bamboo's functionally graded hierarchical structure: underlying mechanisms. Acta biomaterialia, 2015, 16: 178-186.

[5] Zeng Q, Li S, Bao X. Study on the influence of bamboo node on mechanical strength of bamboo. Forestry Science, 1992, (03):247-252.

[6] Yu D, Tan H, Ruan Y. A future bamboo-structure residential building prototype in China: Life cycle assessment of energy use and carbon emission. Energy and Buildings, 2011, 43(10): 2638-2646.

[7] Li H, Zhang Y. Analysis on ecological architectural material of bamboo. Building Science, 2007, (08):20$26+31$

[8] Van der Lugt P, Van den Dobbelsteen A, Janssen J J A. An environmental, economic and practical assessment of bamboo as a building material for supporting structures. Construction and Building Materials, 2006, 20(9): 648-656.

[9] Shao Z, Huang S, Wu F, Zhou L, Clement. A. A Study on the difference of structure and strength between internodes and nodes of Moso bamboo. Bamboo Research Journal, 2008, (02):48-52.

[10] Espiloy Z B. Physico-mechanical properties and anatomical relationships of some Philippine bamboos. International Bamboo Workshop. China. 1985: 257-264.

[11] Oka G M, Triwiyono A, Awaludin A, et al. Effects of node, internode and height position on the mechanical properties of Gigantochloa atroviolacea bamboo. Procedia Engineering, 2014, 95: 31-37.

[12] Shao Z P, Zhou L, Liu Y M, et al. Differences in structure and strength between internode and node sections of moso bamboo. Journal of Tropical Forest Science, 2010: 133-138.

[13] Zhang H, Zhang R, Liu H, Gao Y. Reverse Modeling and finite element analysis of automobile rear axle housing. Tractor and Agricultural Transport Vehicle, 2015, 42(01):10-12.

[14] Hu Y. The application of Geomagic Studio software in reverse engineering post-processing. Manufacturing Automation, 2009, 9: 135-137. 